\title{
THEMATIC PAPER \\ 52 degrees south: mental health services in the Falkland Islands
}

mhGAP training has been proved to be effective to improve the trainees' knowledge and attitudes towards people with mental disorders, but close monitoring and supervision is needed to change their clinical practice.

It is crucial to raise awareness on mental health and also on the availability of mental health services to increase help-seeking behaviour. Awareness raising and mental health service capacity building need to go hand in hand.

Weak health information systems make monitoring and evaluation difficult. There is a need to integrate and strengthen health information systems, and to report on a core set of mental health indicators.

Mental health has been included in Sustainable Development Goals (United Nations 2016); for example, target 3.4 states: 'By 2030, reduce by one third premature mortality from non-communicable diseases through prevention and treatment and promote mental health and well-being'. Target 3.c recommends an increase in the health workforce in SIDS: 'Substantially increase health financing and the recruitment, development, training and retention of the health workforce in developing countries, especially in least developed countries and small island developing States'. To realise these targets by 2030 , countries need to invest more in mental health, especially in human resources. Mental health services do not require expensive equipment, but they do need more trained human resources. mhGAP is one effective solution, but there is also need to increase human resources at all levels - specialists, non-specialists and community/village health workers.

\section{References}

United Nations (2016) Sustainable Development Goals. UN. Available at https://sustainabledevelopment.un.org/sdgs (accessed 1 November 2016).

World Health Organization (2008) mhGAP: Mental Health Gap Action Programme: Scaling up Care for Mental, Neurological, and Substance Use Disorders. WHO. Available at http://www.who.int/ mental_health/evidence/mhGAP/en/ (accessed 1 November 2016).

World Health Organization (2010) mhGAP Intervention Guide for Mental, Neurological and Substance Use Disorders in Non-Specialized Health Settings. WHO. Available at http://www.who.int/ mental_health/publications/mhGAP_intervention_guide/en/ (accessed 1 November 2016).

World Health Organization (2016) mhGAP Intervention Guide for Mental, Neurological and Substance Use Disorders in Non-Specialized Health Settings - Version 2.0. WHO. Available at http://www.who.int/ mental_health/mhgap/mhGAP_intervention_guide_02/en/ (accessed 1 November 2016).

\section{Karen Rimicans ${ }^{1}$ and Tim McInerny ${ }^{2}$}

${ }^{1} \mathrm{RMN}$, Specialist Practitioner in Community Mental Health Nursing, Nurse Teacher, and Senior Community Psychiatric Nurse, Falkland Islands

${ }^{2}$ Visiting Psychiatrist, Falkland Islands; South London and Maudsley National Health Service Foundation Trust, Bethlem Royd Hospital, Beckenham, UK. email im. im.mcinerny@slam.nhs.uk

Conflicts of interest. None.

doi:10.1192/bji.2017.15

(c) The Authors 2018. This is an Open Access article, distributed under the terms of the Creative Commons Attribution-

NonCommercial-NoDerivatives licence (http://creativecommons. org/licenses/by-nc-nd/4.0/), which org/icenses/by-nc-nd/4.0/), which permits non-commercial re-use, distribution, and reproduction in any medium, provided the original work is unaltered and is properly cited. The written permission of Cambridge University Press must be obtained for comPress must be obtained for commercial re-use or in order to create a derivative work.
This article discusses the factors that have shaped the development of the new mental health legislation within the Falkland Islands. The process of implementing new legislation within this remote island community is discussed, including the aspirations underlying the new legislation, the management of psychiatric emergencies and the needs of the clinical team.

The management of mental health needs in the British Overseas Territories is influenced by many factors, including economic capacity to invest in services, organisational structure and resources, perceptions of mental health need and the accessibility of mental health resources within neighbouring countries or the UK.

The Falkland Islands are self-governed and self-funded with the exception of defence. Public administration, including health and education, operate in parallel to English systems with local adaptations in place.
The Falkland Islands are situated approximately 8000 miles from the UK and 400 miles from South America. The islands are geographically remote with limited access by sea and air. There are 700 islands, of which 50 are sparsely populated, spread across an area of 12000 square miles. The Falkland Islands have 2931 residents, composed of islanders mainly of British descent who immigrated in the 1800 s, and expatriates from the UK, St Helena, Chile, Peru, the Philippines and other countries. Of the residents, $62 \%$ have lived in the islands for more than 10 years. The majority of people live in Stanley, the capital of the islands, while the remainder live in Camp, the local term for the countryside outside Stanley (Falkland Islands Government, 2015).

Transient visitors to the islands include seafarers and fishermen who work on the international commercial fishing ships within Falkland Islands waters. The fishing industry has a unique working environment and holds the unenviable rank of highest occupational mortality rate, with fishermen being considered 52.4 times more likely to have a fatal accident at work relative to other 
occupations in Great Britain (Roberts, 2002, p. 544). The health service provides emergency medical and psychiatric treatment for injured fishermen. Fishermen bring their own unique health challenges as well as a range of social, economic, spiritual and cultural needs. Providing healthcare for foreign fishermen can have a significant impact on local resources.

\section{Health service provision within the Falkland Islands}

Mental health services consist of a visiting liaison consultant psychiatrist who provides outpatient clinics twice per year and year-round advice to the clinical team; a child and adolescent consultant clinical psychologist providing an annual clinic and clinical supervision for the school nurse, and the two community psychiatric nurses (CPNs), who are employed locally. The visiting psychiatrist is a forensic specialist based in the UK; this ensures that the psychiatrist is skilled in risk assessment, mental health law and offender management in addition to general liaison duties. This has proven invaluable in this remote community.

Assessment and treatment of mental disorders is provided by the CPNs in conjunction with their medical colleagues. Community and in-patient treatments involving psychological therapies, psychoeducation and guided self-help cognitivebehavioural therapy are available, plus a more limited range of psychopharmaceuticals compared with that available in the UK.

Mental disorders such as anxiety, depression and alcohol abuse are most prevalent, while rates of enduring mental illnesses such as schizophrenia and bipolar affective disorder are low (Fig. 1). Child safeguarding issues present challenges for local services. Sexual offender assessment and rehabilitation is provided by the probation officer in collaboration with the visiting psychiatrist, Social Services, CPNs and other agencies as required.

The King Edward VII Memorial Hospital in Stanley is a small general hospital where the healthcare needs of all local residents and visitors are met, including the needs of those with acute mental

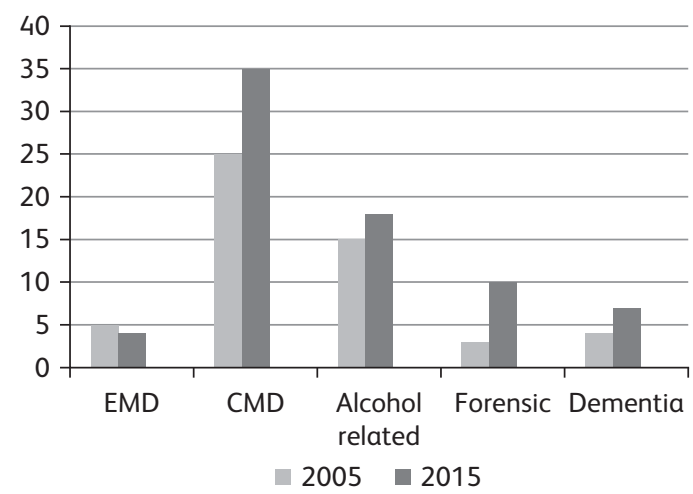

Fig. 1

Overview of Consultant Psychiatrist outpatient clinic, 2005 and 2015. EMD, enduring mental illness; CMD, common mental illness (anxiety and depression). health problems. When emergency or complex treatment is required, services are sought in the UK or, in some circumstances, Chile or Uruguay. The expectation of the clinical team is to treat patients holistically, bridging the gap between mental health and general hospital care, as there are no dedicated psychiatric in-patient facilities or staff. Approximately 5\% of all admissions to the hospital are mental health related, although a minority of hospital admissions will necessitate applying mental health legislation. Similar proportions of acute mental health presentations have been found in remote rural regions of Canada, Australia and New Zealand (Happell \& PlantaniaPhung, 2005; Kim et al, 2011).

\section{Creating a new Mental Health Ordinance}

The former Mental Health Ordinance (MHO) of 1987 had no right of appeal, no access to legal advice, and no right of information for the patient and relatives; no requirement for police officers who had powers of arrest and detention to have any mental health knowledge; and no requirement for clinical professionals involved to have specific MHO training. A patient could be detained for 1 year on the authorisation of a single doctor. Such an MHO was incompatible with the European Convention of Human Rights, to which the Falkland Islands are subject.

In 2006, a working group was convened comprising the visiting psychiatrist, Chief Medical Officer, senior CPN, social work team leader, Senior Crown Counsel, Senior Magistrate and Police Inspector. The working group met with elected politicians and consulted the wider public through local media and Team Tranquil, the local mental health charity, to agree the proposals. Mental health law in other small countries was considered. A mental health bill was drafted locally, and advice was sought from the Mental Health Unit of the UK Ministry of Justice, which approved the detailed proposals. The new MHO was enacted as law by the Legislative Assembly in July 2010. A code of practice was then devised in 2010 in consultation with key stakeholders, such as the ward manager (Falkland Islands Government, 2010). Section forms and information leaflets for patients, nearest relatives and the general public were drafted. The MHO came into force on 1 November 2010.

The principles of the MHO follow the English and Welsh Mental Health Act 2007, namely those of purpose, least restriction, respect, participation, effectiveness, efficiency and equity. The MHO allows the police powers to transfer individuals to hospital for assessment. Approved Doctors can detain a patient for up to $72 \mathrm{~h}$; if an Approved Professional agrees during this period, the detention can continue for up to 6 months. Those who are detained receive written and verbal instruction on their rights, with access to legal advice and a right of appeal to an independent Mental Health Tribunal. Where English is not the person's first language, access to a local 
interpreter or telephone interpreter is provided. The code of practice handbook clarifies the requirements of Approved Practitioners. All doctors, nurses and social workers have to attend MHO training run by the visiting psychiatrist and senior mental health nurse every 5 years to achieve Approved status.

A Mental Health Tribunal must convene within 14 days of an appeal being lodged. A tribunal comprises the Senior Magistrate and two Justices of the Peace (JPs), or three JPs If the Senior Magistrate is unavailable. If statutory criteria for detention are not met, the tribunal is obliged to discharge the patient from section.

The Falkland Islands Constitution 2008 states that any detained person with a mental disorder, including a Falkland Islander, may be removed from the islands against their wishes for treatment in the UK or, in some instances, Chile or Uruguay. This Overseas Removal Order is made by the Chief Medical Officer to the Mental Health Tribunal, which must be satisfied that the mental disorder cannot be effectively treated in the Falkland Islands and that removal is necessary in the interests of the person or to protect the public. Seeking overseas treatment through the $\mathrm{MHO}$ is an infrequent occurrence and is primarily required for treatment of acute psychiatric episodes that necessitate in-patient care beyond what can be provided locally. By questioning clinical decisions, the Mental Health Tribunal ensures the principles of the MHO are respected and safeguards patients' best interests and rights.

Overseas treatment understandably leads to extreme separation of patients from relatives and the local community, and challenges in planning return following recovery. Islanders are, however, used to such complications, knowing the limitations of their remote geographical location, and appreciate the need for safe, specialised overseas care, whether for medical or psychiatric emergencies.

\section{Clinical challenges in a remote community}

The provision of mental health services within a remote community brings both challenges and rewards. Challenges include setting clinical boundaries and patient confidentiality, where treating colleagues, family and friends can be an issue. Sensitivity to the needs of the community and cultivating good working relationships are essential. The local team takes pride in its resourcefulness and finding solutions to problems can be rewarding; however, ensuring that adequate resources are available to provide good-quality care requires investment, forward thinking and recognition of the diverse needs that can stretch resources, to avoid any undue strain on service providers.

Maintaining professional expertise remains a challenge in a context where mental health skills are more than knowledge and experience, but also acceptance of the limitations around clinical practice. Training devised to develop local mental health skills and disseminate the MHO has been implemented since 2010. Teaching strategies include multi-agency case management roleplays, tabletop exercises and 'fire drills', coupling problem-solving with familiarisation with the MHO paperwork necessary when dealing with a psychiatric emergency. Providing training has benefits including increased staff confidence and the development of a 'cultural and community understanding', which helps to create a team response to managing challenging clinical problems (Strasser \& Neusy, 2010, p. 780). The current trend towards clinical specialism within the field of mental health practice is superfluous in remote areas, where specialist generalists with a broad knowledge base across the spectrum of mental healthcare are required.

\section{Future challenges}

Exploring the effectiveness of the MHO, identifying positive patient outcomes, analysis of clinical practice and risk management are other areas for future development.

Ensuring that adequate resources and mechanisms are in place to maintain consistent good clinical practice is an ongoing challenge. Staff turnover leads to knowledge deficits, which can be countered by regular commitments to provide training by mental health professionals. Since 2010 , over 150 professionals have received MHO training, including legal advisors, police officers, social workers, registered nurses and doctors, while over 100 qualified and unqualified health workers have participated in mandatory training to ensure safe and effective team work when managing psychiatric emergencies. Acknowledgement of the need for mental health skills across clinical roles, through investing in people and continuing professional education, is essential (Harrison \& Hart, 2006, p. 27).

The government has recognised that the hospital, as the designated place of safety, currently provides inadequate resources for acutely behaviourally disturbed patients and plans to create an admission suite that is safe for all patients. Any increase in acute admissions will have an impact on local resources, so close monitoring of the balance between demand and resources is required.

\section{References}

Falkland Islands Government (2010) Mental Health Ordinance. Attorney Generals Chambers, Stanley.

Falkland Islands Government (2015) Statistical Year Book 2014 , Policy and Planning. Falkland Islands Government Secretariat, Stanley.

Happell B. \& Plantania-Phung C. (2005) Mental health issues within the general health care system: The challenge for nursing in Australia. Nurse Education Today, 25, 465-471.

Harrison A. \& Hart C. (2006) Mental Health Care for Nurses: Applying Mental Health Skills in the General Hospital Setting. Blackwell Publishing. 
Kim C. S., Ideker K. \& Todicheeney-Mannes D. (2011) Usefulness of Aggressive Behaviour Risk Assessment Tool for prospectively identifying violent patients in medical and surgical units. Journal of Advanced Nursing, 68, 349-357.
Roberts S. E. (2002) Hazardous occupations in Great Britain. Lancet, $360,543-544$

Strasser R. \& Neusy A. J. (2010) Context counts: training health workers in and for rural and remote areas. World Health Organisation Bulletin, 88, 777-782.

\title{
THEMATIC PAPER
}

\section{Psychiatry in Shetland}

\author{
Martin Scholtz ${ }^{1}$ and Almarie Harmse ${ }^{2}$
}

${ }^{1}$ Consultant General Adult Psychiatrist, Dorset HealthCare University NHS Foundation Trust, UK; email martin.scholtz@nhs.net ${ }^{2}$ Specialty Doctor in Psychiatry, NHS Shetland, UK

\section{Conflicts of interest. None.}

Keywords. Rural psychiatry; personality disorders; reducing hospital admissions.

doi:10.1192/bji.2018.2

(c) The Authors 2018. This is an Open Access article, distributed under the terms of the Creative Commons AttributionNonCommercial-NoDerivatives licence (http://creativecommons. org/licenses/by-nc-nd/4.0/), whic whic permits non-commercial re-use, distribution, and reproduction in any medium, provided the original work is unaltered and is properly cited. The written permission of Cambridge University Press must be obtained for comPress must be ob mercial re-use or in order to create a derivative work.
The Shetland Isles are a place of breathtaking landscapes and pristine wildlife. As harsh as the weather can be, so warm and welcoming are the people and their proud half-Scottish, half-Scandinavian culture. Practising psychiatry in this northernmost outpost of the UK involves significant challenges. The authors were the only two psychiatrists based on this remote island group, which is home to 23000 people.

\section{Where is Shetland?}

Shetland is Britain's northernmost community - a group of over 100 islands, 15 of which are inhabited. The main town, Lerwick, is 217 miles north of Aberdeen. Norway is just over 200 miles to the east and the Faroe Islands lie a similar distance to the north-west, with Iceland only another 300 miles beyond Faroe. The Shetland Island group stretches a hundred miles from north to south and lies at a latitude of 60 degrees north. This is as far north as St Petersburg and Anchorage, but warm ocean currents give Shetland significantly milder temperatures. The average wind speed over the year is around force 4, and wind speeds of hurricane force 12 are not unknown in winter. Shetland is served by commercial flights from five Scottish airports and by an overnight ferry from Aberdeen (Shetland.org, 2018).

\section{Historical overview of the Shetland Isles}

Shetland was inhabited by Neolithic farmers by 3000 BC. Viking invasions started around 800 $\mathrm{AD}$, with Shetland part of the Pictish culture prior to the arrival of the Vikings. Norse (Viking) rule ended as the result of a marriage treaty in 1468 between James III of Scotland and Margaret, a Danish princess. The Danish struggled to raise the funds for Margaret's dowry, so that Shetland was mortgaged to Scotland (Shetland. org, 2018).

After the Norse warlords, came four centuries when Shetland sold its salted fish to the outside world through the Hanseatic League of merchants, based in Bergen, Bremen, Lubeck and Hamburg. After the 1707 Treaty of Union, the new British government ousted the Hansa and, during the 18th century, local merchantlairds ruled the land by means of a feudal system and built lavish mansions (known as Haa houses) in every part of Shetland.

The First World War destroyed the markets for the booming herring fisheries, which at the turn of the century had lifted many islanders out of poverty, and emigration increased during most of the 20th century. During the Second World War, Shetland was the base for a secret and dangerous operation that saw small fishing boats, known as the Shetland Bus, supporting the Norwegian resistance against Nazi occupation.

By 1971, the population had dropped to just 17325 compared with 31670 in 1861 . However, a home-grown revival based on fishing, agriculture, knitwear and tourism made Shetland's economy grow so strongly that, when oil and gas were discovered offshore in the early 1970s, the Council was able to strike a remarkable deal that gave Shetland a share of oil revenues.

\section{Culture}

For historical reasons, Shetland has maintained a close relationship with Norway. The dialect spoken by Shetlanders contains many Old Norse words. The houses that people build in Shetland are often in a Scandinavian style and indeed are sometimes supplied from Norway. Norwegian flags are also commonly seen, and place-names are almost exclusively Norse. In Lerwick, many street names celebrate Norse figures such as King Harald. The spectacular annual Up-HellyAa fire festival is Shetlanders' celebration of their rich Viking heritage. Shetland has a vibrant art scene and is popular with artists, writers, poets, photographers, musicians, architects, textile designers and a wide range of craftspeople from all over the world. Several music festivals take place during the year, including the worldrenowned Shetland Folk Festival (Shetland.org, 2018). 